\title{
The Drainage Consolidation Modeling of Sand Drain in Red Mud Tailing and Analysis on the Change Law of the Pore Water Pressure
}

\author{
Chuan-sheng Wu ${ }^{1,2}$ \\ ${ }^{1}$ State Key Laboratory of Coal Mine Disaster Dynamics and Control, Chongqing University, Chongqing 400044, China \\ ${ }^{2}$ Mining Engineering Post-Doctoral Mobility Station, Chongqing University, Chongqing 400044, China
}

Correspondence should be addressed to Chuan-sheng Wu; 50741033@qq.com

Received 26 December 2013; Accepted 11 June 2014; Published 22 July 2014

Academic Editor: Vassilios C. Loukopoulos

Copyright (C) 2014 Chuan-sheng Wu. This is an open access article distributed under the Creative Commons Attribution License, which permits unrestricted use, distribution, and reproduction in any medium, provided the original work is properly cited.

\begin{abstract}
In order to prevent the occurring of dam failure and leakage, sand-well drainages systems were designed and constructed in red mud tailing. It is critical to focus on the change law of the pore water pressure. The calculation model of single well drainage pore water pressure was established. The pore water pressure differential equation was deduced and the analytical solution of differential equation using Bessel function and Laplace transform was given out. The impact of parameters such as diameter $d$, separation distance $l$, loading rate $q$, and coefficient of consolidation $C_{v}$ in the function on the pore water pressure is analyzed by control variable method. This research is significant and has great reference for preventing red mud tailings leakage and the follow-up studies on the tailings stability.
\end{abstract}

\section{Introduction}

Red mud, a by-product of alumina refining, is produced in increasing quantities globally $[1,2]$. Much of this red mud has traditionally been produced by methods which create a liquor of high moisture content $[3,4]$, which are deposited in impoundments that can reach depths of $20 \mathrm{~m}$ [5-7]. Red mud in this tailing is infiltrated by water and in a status of saturation, resulting in a low strength and high moisture content. As a consequence, the continuous stacking of Sintering red mud into this tailing might cause the dam failure and the leak-prone of the tailing when the original designed seepage prevention rank is low, especially for the tailing built in Karst area [8,9]. As the mineral and chemical composition of red mud is very complex, red mud and its attached fluid have strong alkalinity and corrosivity $[10,11]$. It is dangerous that the failure and leakage of this tailings dam occurs and further cause serious consequences that widespread environmental pollution $[12,13]$.

To prevent the occurring of dam failure and leakage, sand well drainage systems were designed and constructed in this red mud tailing, the lower part of which is mainly soft Bayer red mud [14]. With the assistance of sand well drainage systems, stacking of sintered dry red mud onto the tailings will promote the drainage of pore water and reinforcement of the basement of the tailings. Simultaneously, the pressure of pore water will change continuously as well [15]. Consequently, it is vital to focus on the law of pore water pressure distribution and change in the lower soft red mud during the stacking of Sintering red mud. There was a great deal of reports on the application of the sand well drainage method and one-dimensional drainage-consolidation calculation for saturated soils since 1930s [16-19]. However, as for the calculation on the drainage-consolidation by sand wells, the most well-known model is undoubtedly the axisymmetric radial drainage-consolidation equations of a single well, which was deduced and proposed by Barron in 1948 [20]. This equation not only gives us the analytical solution under both the conditions of isostrain and free strain, but also has considered the fluid seepage flowing-strain interaction.

In this theoretical research field of the in soft soil foundation, although a solution to this compound problem 


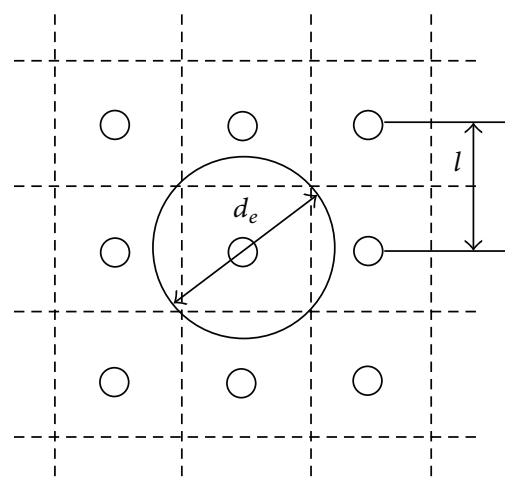

(a)

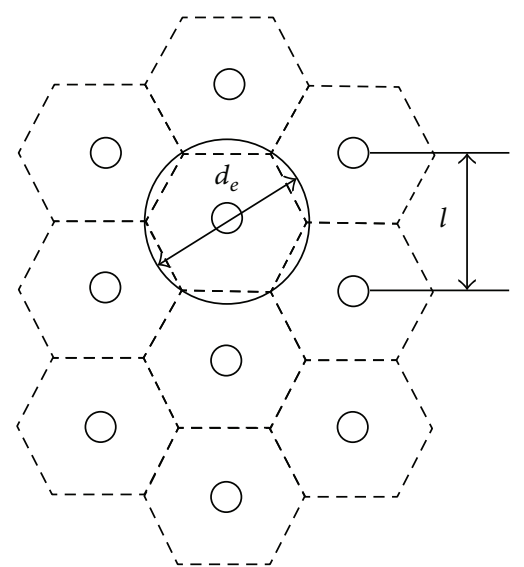

(b)

FIGURE 1: Two distribution modes of sand drains: (a) square; (b) triangle.

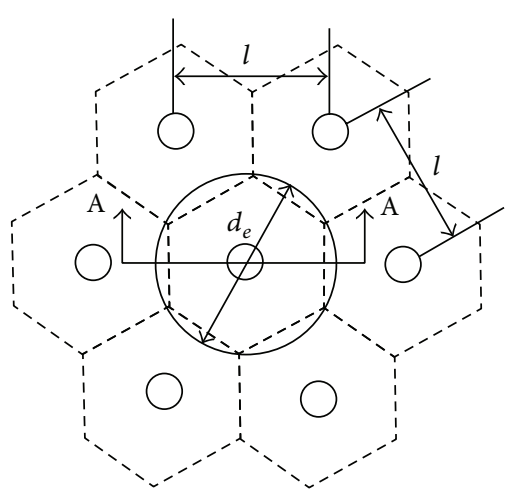

(a)

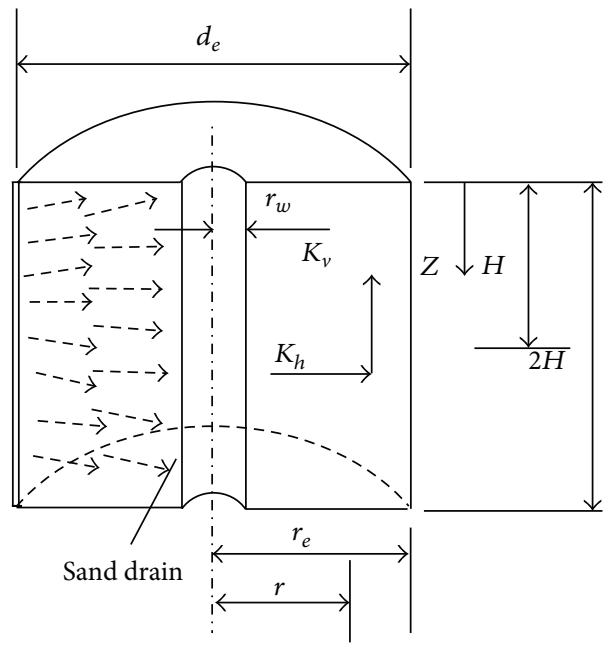

(b)

FIGURE 2: The computational model of one sand drain: (a) the floor plan; (b) A-A section plan.

has been given with the help of the three-dimensional parabolic equation under the 2 nd type boundary condition, yet, regretfully, it has no sufficient accuracy [21-23]. Therefore, it is important to give an accurate solution to this equation. This research aims at giving the analytical solution of hydrostatic pressure of the three-dimensional consolation utilizing the mathematical calculation methods such as Laplace transform. Crucially, this solution has a high applicability. This research is significantly important to the calculation of pore water pressure and the further control of leakage. In addition, it can theoretically support the follow-up studies on the tailings stability.

\section{Physical Model of the Drainage Consolidation System}

Because of the large area and complex shape of the red mud tailings researched in this project, the theoretical calculation is difficult to be carried out without reasonable simplification and the further construction of calculation model. The sand drains are designed and sited uniformly and equally, which means that these sand drains are alike in function and effect. Then, the drainage consolidation of the whole tailing red mud can be obtained through research on each sand drain and their superposition. The schematic diagram of two wellaccepted distribution modes of sand drains are shown as in Figure 1. In addition, the smear zone formed as a result of construction disturbance when the sand drain separation distance is lower than $1.0 \mathrm{~m}$ [24]. It can be overlooked when the sand drain separation distance is larger than that of building and road foundation engineering [25]. In addition, seepage resistance caused by the material type of the sand drains, for the piling rate is low and the drainage time is long. As for the piling of the red mud, it can be assumed to be continuous and the production of aluminum as well.

As referred before, the affection region of each sand drain could be equivalent to a cylinder (Figure 2). The equivalent 


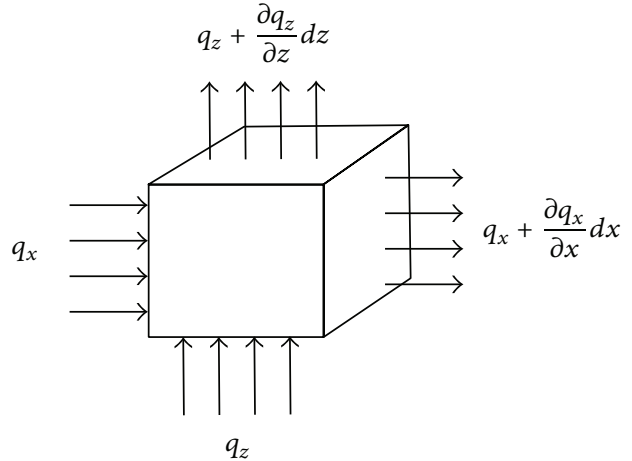

Figure 3: The diagram of an element in the seepage calculation.

diameter can be deduced from the equation of $d_{e}=\alpha_{1} l$, where $l$ refers to the sand drain separation distance [26]. The value of $\alpha_{1}$ would be 1.13 when it comes to square-like sand drain distribution and 1.05 for triangle-like one. We will also give the assumption that the seepage of pore water contained in the affection cylinder region would be along the radial direction towards the sand drain and then along the vertical direction towards the underground.

\section{Derivation of Pore Pressure Function of the Red Mud Foundation with Sand Drain}

In Barron's theoretical research, although a solution to this compound problem has been given with the help of the threedimensional parabolic equation under the 2 nd type boundary condition, this solution is not accurate. We have tried to calculate the analytical solution of hydrostatic pressure of the three-dimensional consolation through the mathematical calculation methods such as Laplace transform.

Following Barron theory, we do the following basic assumptions for the consideration of pore water pressure under variable load change:

(1) the soil skeleton is isotropic material, regardless of the efficiency of the soil mass deformation and creep;

(2) soil particle and pore water can not be compressed;

(3) seepage flow both in vertical and horizontal radial directions obeys Darcy's law and have the same permeability coefficient;

(4) soil particles move in the vertical direction; the applied load is a first-order function of time.

Take a cell cube from the computational domain as shown in Figure 3 and set that a unit of the $x$ direction is $d x$ and a unit of the $z$ direction is $d z$. So, the amount of soil volume change during the process of drainage consolidation is equal to the amount of pore water. Consider

$$
\Delta V=\Delta Q
$$

Consider the seepage flow balance both in horizontal and vertical directions as follows:

$$
\begin{gathered}
\frac{\partial V}{\partial t} d t=\frac{\partial q_{z}}{\partial z} d x d z \cdot d t+\frac{\partial q_{x}}{\partial x} d z d x \cdot d t \\
\Delta V=e\left(\frac{1}{1+e_{0}} d x d z\right),
\end{gathered}
$$

where $e$ is the void ratio of time $t$, and void ratio of time $t=0$ is $e_{0}$. Take this into (2) and then get

$$
\begin{aligned}
e\left(\frac{1}{1+e_{0}} d x d z\right) \cdot d t= & \frac{\partial q_{z}}{\partial z} d x d z \cdot d t \\
& +\frac{\partial q_{x}}{\partial x} d z d x \cdot d t
\end{aligned}
$$

And by the compression test curve, we have

$$
\frac{\partial e}{\partial t}=a \frac{\partial u}{\partial t},
$$

where $a$ is a compression coefficient. Putting (5) into (4) can deduce

$$
\begin{aligned}
\left(\frac{\alpha}{k\left(1+e_{0}\right)}\right) \cdot \frac{\partial u}{\partial t} d x d z \cdot d t= & \frac{\partial q_{z}}{\partial z} d x d z \cdot d t \\
& +\frac{\partial q_{x}}{\partial x} d z d x \cdot d t
\end{aligned}
$$

where $k$ is osmotic coefficient, and

$$
\frac{\partial^{2} u}{\partial t^{2}}=\frac{\partial q_{x}}{\partial x}+\frac{\partial q_{y}}{\partial y}+\frac{\partial q_{z}}{\partial z}
$$

which can be put into (6) to get

$$
C_{v} \cdot \frac{\partial u}{\partial t}=\frac{\partial^{2} u}{\partial x^{2}}+\frac{\partial^{2} u}{\partial y^{2}}+\frac{\partial^{2} u}{\partial z^{2}}
$$

where $C_{v}$ represents the vertical coefficient of consolidation. It can be calculated from $\alpha$ by the definition formula $C_{v}=$ $\left((1+e) /\left(\rho_{w} \cdot \alpha\right)\right) k$, where $\rho_{w}$ is the density of water. That means $C_{v}$ can be gotten from the data of both consolidation test and penetration test.

Change the former equation to accord with the specific boundary of sand drain:

$$
C_{v} \cdot \frac{\partial u}{\partial t}=\frac{\partial^{2} u}{\partial z^{2}}+\frac{1}{r} \frac{\partial u}{\partial r}+\frac{\partial^{2} u}{\partial r^{2}}
$$

According to the single well drainage consolidation model shown in Figure 2, the upper boundary has curtained pore pressure, the left one is water-proof, the right is sand drain, and the physical radius and action radius of which are separately $r_{w}$ and $r_{e}$. Then, the drainage consolidation with 
the addiction of boundary conditions can be modeled as the following mathematical physical equation:

$$
\begin{gathered}
\frac{\partial u}{\partial t}=C_{v}\left(\frac{\partial^{2} u}{\partial r^{2}}+\frac{1}{r} \frac{\partial u}{\partial r}+\frac{\partial^{2} u}{\partial z^{2}}\right), \\
\left.u(z, r, t)\right|_{t=0}=p_{0}, \quad r_{w} \leq r \leq r_{e}, 0<z<H, \\
\left.u(z, r, t)\right|_{z=0}=0, \\
\left.u(z, r, t)\right|_{r=r_{w}}=0,\left.\quad u_{r}(z, r, t)\right|_{r=r_{e}}=0, \\
\lim _{t \rightarrow \infty} u(z, r, t)=0 .
\end{gathered}
$$

In this equation, $u(z, r, t)$ is excess hydrostatic pressure; $r$ is pole diameter of the cylindrical polar coordinates, flow coordinates; $t$ is consolidation time, flowing coordinates; $z$ is coordinates for vertical flow, calculation depth; $p$ is additional load, time function of $t ; C_{v}$ is the consolidation coefficient, determined by experiment; $H$ is soil drainage distance, soil thickness, which is constant.

In addition, $p(t)=p_{0}+q \cdot t$, which refers to the additional load from the factory produced upper part of Bayer dry red mud, is linear. The $q$ is the loading velocity.

According to the theory of soil mechanics, the threedirection water flow in the soil is believed to be turbulent flow problem and can be converted into two parts, planar radial flow (or radiation) and vertical (or linear) laminar flow problem. Based on mathematical method, the total three direction water flow problem also can be transformed to subproblem I and subproblem II.

Subproblem I is

$$
\begin{gathered}
\frac{\partial u_{1}}{\partial t}-\frac{\partial \Theta_{1}}{\partial t}=C_{v z} \frac{\partial^{2} u_{1}}{\partial z^{2}} ; \\
\left.u_{1}(z, t)\right|_{t=0}=p_{0} ; \\
\left.u_{1}(z, t)\right|_{z=0}=0 ; \\
\lim _{t \rightarrow \infty} u_{1}(z, t)=0 .
\end{gathered}
$$

Subproblem II is

$$
\begin{gathered}
\frac{\partial u_{2}}{\partial t}-\frac{1}{2} \frac{\partial \Theta_{2}}{\partial t}=C_{v r}\left(\frac{1}{r} \frac{\partial u_{2}}{\partial r}+\frac{\partial^{2} u_{2}}{\partial r^{2}}\right) \\
\left.u_{2}(r, t)\right|_{t=0}=p_{0} \\
\left.u_{2}(r, t)\right|_{r=r_{w}}=0 \\
\left.\frac{\partial u_{2}}{\partial r}\right|_{r=r_{e}}=0 \\
\lim _{t \rightarrow \infty} u_{2}(r, t)=0
\end{gathered}
$$

Assuming the solution of subproblem $\mathrm{I}$ is $u_{1}(z, t)$ and solution of subproblem II is $u_{2}(r, t)$, then the solution to the total question $u(z, r, t)$ must be confirmed to the form of

$$
\frac{u(z, r, t)}{u_{0}}=\frac{u_{1}(z, t)}{u_{0}} \cdot \frac{u_{2}(r, t)}{u_{0}}
$$

or

$$
u(z, r, t)=\frac{u_{1} u_{2}}{u_{0}}=\frac{u_{1} u_{2}}{p_{0}}
$$

3.1. The Theoretical Solution of Subproblem II. In (12), there is

$$
\Theta_{2}=\sigma_{x}+\sigma_{y}=\frac{2 v p(t)}{1-v},
$$

where $v$ is Poisson ratio of soil; $r_{e}$ is the action radius of sand drain, half of the sand drain separation distance; $r_{w}$ is the physical radius of sand drain; $C_{v r}$ is coefficient of consolidation in horizontal direction.

Equation (15) is the resolution of stress with the assumption that the soil is linear elasticity. Put (15) into (12) and then it can be deduced that

$$
\frac{\partial u_{2}}{\partial t}-\frac{q v}{1-v}=C_{v r}\left(\frac{1}{r} \frac{\partial u_{2}}{\partial r}+\frac{\partial^{2} u_{2}}{\partial r^{2}}\right) .
$$

Equation (16) is the equilibrium equation in horizontal direction which can be rewritten as

$$
\frac{\partial u_{2}}{\partial t}-Q=C_{v r}\left(\frac{1}{r} \frac{\partial u_{2}}{\partial r}+\frac{\partial^{2} u_{2}}{\partial r^{2}}\right)
$$

where $Q=q v /(1-v), q$ is engineered loading velocity. Both $Q$ and $q$ are constant. Equation (17) can be further deduced as follows by Laplace transformation:

$$
s U_{2}-\frac{Q}{s}=C_{v r}\left(\frac{1}{r} \frac{\partial U_{2}}{\partial r}+\frac{\partial^{2} U_{2}}{\partial r^{2}}\right) .
$$

Equation (18) can be solved as

$$
\frac{1}{r} \frac{\partial U_{2}}{\partial r}+\frac{\partial^{2} U_{2}}{\partial r^{2}}-\frac{s U_{2}}{C_{v r}}+\frac{Q}{s C_{v r}}=0 .
$$

Bessel solution of (19) can be calculated as

$$
U_{2}(s, r)=\frac{Q}{s^{2}}+C_{1} J_{0}\left(\frac{i r \sqrt{s}}{\sqrt{C_{v r}}}\right)+C_{2} Y_{0}\left(\frac{i r \sqrt{s}}{\sqrt{C_{v r}}}\right) .
$$

Equation (20) can be transformed into

$$
U_{2}(s, r)=\frac{Q}{s^{2}}+C_{1} J_{0}\left(\frac{r \sqrt{-s}}{\sqrt{C_{v r}}}\right)+C_{2} Y_{0}\left(\frac{r \sqrt{-s}}{\sqrt{C_{v r}}}\right) .
$$

Assume $\tau=-s$, and then it can be deduced to

$$
U_{2}(\tau, r)=\frac{Q}{s^{2}}+C_{1} J_{0}\left(\frac{r \sqrt{\tau}}{\sqrt{C_{v r}}}\right)+C_{2} Y_{0}\left(\frac{r \sqrt{\tau}}{\sqrt{C_{v r}}}\right) .
$$

The $C_{1}$ and $C_{2}$ can be calculated by the boundary conditions in (12),

$$
\begin{aligned}
C_{1} & =\frac{Q Y_{1}\left(A r_{e}\right)}{s^{2}\left(J_{1}\left(A r_{e}\right) Y_{0}\left(A r_{w}\right)-J_{0}\left(A r_{w}\right) Y_{1}\left(A r_{e}\right)\right)}, \\
C_{2} & =\frac{Q J_{1}\left(A r_{e}\right)}{-s^{2}\left(J_{1}\left(A r_{e}\right) Y_{0}\left(A r_{w}\right)+J_{0}\left(A r_{w}\right) Y_{1}\left(A r_{e}\right)\right)},
\end{aligned}
$$


where $A=\sqrt{\tau / C_{v r}}$ and (24) can be deduced as

$$
\begin{aligned}
U_{2}(\tau, r)= & \frac{Q}{\tau^{2}} \\
& +\frac{Q Y_{1}\left(A r_{e}\right) J_{0}(A r)}{\tau^{2}\left(J_{1}\left(A r_{e}\right) Y_{0}\left(A r_{w}\right)-J_{0}\left(A r_{w}\right) Y_{1}\left(A r_{e}\right)\right)} \\
& +\frac{Q J_{1}\left(A r_{e}\right) Y_{0}(A r)}{-\tau^{2}\left(J_{1}\left(A r_{e}\right) Y_{0}\left(A r_{w}\right)+J_{0}\left(A r_{w}\right) Y_{1}\left(A r_{e}\right)\right)}
\end{aligned}
$$

Equation (25) can be simplified as

$$
U_{2}(\tau, r)=\frac{Q G(\tau)+Q Y_{1}\left(A r_{e}\right) J_{0}(A r)-Q J_{1}\left(A r_{e}\right) Y_{0}(A r)}{\tau^{2} G(\tau)} .
$$

In this equation, $G(\tau)=\left(J_{1}\left(A r_{e}\right) Y_{0}\left(A r_{w}\right)-J_{0}\left(A r_{w}\right) Y_{1}\left(A r_{e}\right)\right)$, (26) can be further deduced as following by anti-Laplace transformation:

$$
u_{2}(t, r)=\frac{1}{2 \pi i} \int_{-\sigma+i \infty}^{-\sigma-i \infty} U(\tau, r) e^{-\tau t} d \tau \quad(t \geq 0) .
$$

Equation (27) can be written as

$$
u_{2}(t, r)=\sum \text { Residues. }
$$

The singularity of (28) is $\tau=0$, and all the null points of $G(\tau)=0$, and the residue of singularity of $\tau=0$ is

$$
\begin{gathered}
\operatorname{Res}\left(\frac{\left(Q G(\tau)+Q Y_{1}\left(A r_{e}\right) J_{0}(A r)-Q J_{1}\left(A r_{e}\right) Y_{0}(A r)\right) e^{-\tau t}}{\tau^{2} G(\tau)},\right. \\
0) \\
=\frac{Q G(0)+Q Y_{1}(0) J_{0}(0)-Q J_{1}(0) Y_{0}(0)}{2 G(0)}=\frac{1}{2} .
\end{gathered}
$$

As for the root of $G(\tau)=0, \tau$ can be replaced by $\beta$ and can certified by $G(\beta)=0$. Then, we have

$$
G(\beta)=\left(J_{1}\left(B r_{e}\right) Y_{0}\left(B r_{w}\right)-J_{0}\left(B r_{w}\right) Y_{1}\left(B r_{e}\right)\right)=0 .
$$

In the equation, we have $B=\sqrt{\beta / C_{v r}}$. The root of formulas $G(\beta)=0, \beta_{i}(i=1,2,3, \ldots)$ can be natural frequency and all are of arithmetic number. Residue, when $s=\beta_{i}$, is

$$
\begin{gathered}
\operatorname{Res}\left(\frac{Q G(\tau)+Q Y_{1}\left(A r_{e}\right) J_{0}(A r)-Q J_{1}\left(A r_{e}\right) Y_{0}(A r) e^{-\tau t}}{\tau^{2} G(\tau)},\right. \\
\left.\beta_{i}\right) \\
=Q \frac{\left[Y_{1}\left(B_{i} r_{e}\right) J_{0}\left(B_{i} r\right)-J_{1}\left(B_{i} r_{e}\right) Y_{0}\left(B_{i} r\right)\right] e^{-\beta_{i} t}}{\left.\left(\beta_{i}^{2}(\partial G(\tau) / \partial \tau)\right)\right|_{\tau=\beta_{i}}},
\end{gathered}
$$

where $B_{i}$ is $B_{i}=\sqrt{\beta_{i} / C_{v r}}$. According to the character of Bessel function, it can be deduced that

$$
\begin{gathered}
\operatorname{Res}\left(\frac{Q G(\tau)+Q Y_{1}\left(A r_{e}\right) J_{0}(A r)-Q J_{1}\left(A r_{e}\right) Y_{0}(A r) e^{-\tau t}}{\tau^{2} G(\tau)},\right. \\
\left.\beta_{i}\right) \\
=Q\left[Y_{1}\left(B_{i} r_{e}\right) J_{0}\left(B_{i} r\right)-J_{1}\left(B_{i} r_{e}\right) Y_{0}\left(B_{i} r\right)\right] e^{-\beta_{i} t} \\
\times\left(\beta_{i}^{2} \frac{r_{e}\left[J_{0}\left(r_{e} B_{i}\right)-J_{2}\left(r_{e} B_{i}\right)\right] Y_{0}\left(r_{w} B_{i}\right)}{4 C_{v r} B_{i}}\right. \\
\left.\quad-\beta_{i}^{2} J_{0}\left(r_{w} B_{i}\right) Y_{1}\left(r_{w} B_{i}\right)\right)^{-1} .
\end{gathered}
$$

Then, the excess hydrostatic pressure can be $u_{2}(t, r)=\frac{1}{2}$

$$
\begin{gathered}
+\sum_{i=1}^{\infty}\left(Q\left[Y_{1}\left(B_{i} r_{e}\right) J_{0}\left(B_{i} r\right)-J_{1}\left(B_{i} r_{e}\right) Y_{0}\left(B_{i} r\right)\right] e^{-\beta_{i} t}\right. \\
\times\left(\beta_{i}^{2} \frac{r_{e}\left[J_{0}\left(r_{e} B_{i}\right)-J_{2}\left(r_{e} B_{i}\right)\right] Y_{0}\left(r_{w} B_{i}\right)}{4 C_{v r} B_{i}}\right. \\
\left.\left.-\beta_{i}^{2} J_{0}\left(r_{w} B_{i}\right) Y_{1}\left(r_{w} B_{i}\right)\right)^{-1}\right) .
\end{gathered}
$$

3.2. The Theoretical Solution of Subproblem I. The kinematic equation of subproblem $I$ is

$$
C_{v z} \frac{\partial^{2} u_{1}}{\partial z^{2}}=\frac{\partial u_{1}}{\partial t}-\frac{\partial \sigma_{z}}{\partial t}=\frac{\partial u_{1}}{\partial t}-q
$$

The boundary conditions are

$$
\begin{gathered}
\left.u_{1}(z, t)\right|_{t=0}=p_{0}, \\
\left.u_{1}(z, t)\right|_{z=0}=0, \\
\left.\frac{\partial u_{1}(z, t)}{\partial z}\right|_{z=H_{0}}=0 .
\end{gathered}
$$

Equation (34) can be further deduced as follows by Laplace transformation:

$$
\begin{gathered}
\left.U_{1}(z, s)\right|_{z=0}=0, \\
\left.\frac{\partial U_{1}(z, s)}{\partial z}\right|_{z=H_{0}}=0 .
\end{gathered}
$$

Solving the upper equations,

$$
\begin{aligned}
U_{1}(z, s)= & C_{3} \sinh \left(\sqrt{\frac{s}{C_{v z}} z}\right)+C_{4} \cosh \left(\sqrt{\frac{s}{C_{v z}} z}\right) \\
& +\frac{q+p_{0} s}{s^{2}} .
\end{aligned}
$$


Putting the boundary conditions can give the value that

$$
\begin{aligned}
C_{3} & =\frac{\left(q+p_{0} s\right) \tanh \left(\sqrt{s / a} H_{0}\right)}{s^{2}}, \\
C_{4} & =\frac{-q+p_{0} s}{s^{2}} .
\end{aligned}
$$

Equation (37) can be deduced as

$$
\begin{aligned}
U_{1}(z, s)= & \frac{\left(-q+p_{0} s\right)}{s^{2} \cosh \left(\sqrt{s / C_{v z}} H_{0}\right)} \\
\times & {\left[\cosh \left(\sqrt{\frac{s}{C_{v z}}} H_{0}\right)-\cosh \left(\sqrt{\frac{s}{C_{v z}}} H_{0}\right)\right.} \\
& \times \cosh \left(\sqrt{\frac{s}{C_{v z}} z}\right)+\sinh \left(\sqrt{\frac{s}{C_{v z}}} H_{0}\right) \\
& \left.\times \sinh \left(\sqrt{\frac{s}{C_{v z}} z}\right)\right] .
\end{aligned}
$$

As for the $s^{2} \cosh \left(\sqrt{s / C_{v z}} H_{0}\right)$, null point of $s$ is

$$
\begin{array}{r}
s=0, \quad s=\frac{(2 k-1)^{2} \pi^{2} C_{v z}}{4 H_{0}^{2}} \\
(k=1,2,3, \ldots) .
\end{array}
$$

Besides, $s=0$ is the moving singularity of $U_{1}(z, s)$; other points are all first grade singularity of $U_{1}(z, s)$. The it can be deduced by the expansion of residue theorem:

$$
\begin{aligned}
& u_{1}(z, t) \\
& =L^{-1}\left[U_{1}(z, s)\right] \\
& =\sum \operatorname{Re} s\left[\frac{\left(q+p_{0} s\right) e^{s t}}{s^{2} \cosh \left(\sqrt{s / C_{v z}} H_{0}\right)}\right. \\
& \times\left[\cosh \left(\sqrt{\frac{s}{C_{v z}}} H_{0}\right)-\cosh \left(\sqrt{\frac{s}{C_{v z}}} H_{0}\right)\right. \\
& \times \cosh \left(\sqrt{\frac{s}{C_{v z}}} z\right)+\sinh \left(\sqrt{\frac{s}{C_{v z}}} H_{0}\right)
\end{aligned}
$$

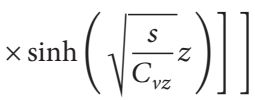

$$
\begin{aligned}
& =\left(\sum _ { k = 1 } ^ { \infty } \left(( - q + p _ { 0 } s ) \left[\cosh \left(\sqrt{\frac{s}{C_{v z}}} H_{0}\right)-\cosh \left(\sqrt{\frac{s}{C_{v z}}} H_{0}\right)\right.\right.\right. \\
& \times \cosh \left(\sqrt{\frac{s}{C_{v z}} z}\right)+\sinh \left(\sqrt{\frac{s}{C_{v z}}} H_{0}\right) \\
& \left.\times \sinh \left(\sqrt{\frac{s}{C_{v z}} z}\right)\right] \\
& \left.\left.\times\left(s^{2} \cosh ^{\prime}\left(\sqrt{\frac{s}{C_{v z}}} H_{0}\right)\right)^{-1}\right) e^{s t}\right)\left.\right|_{s=-\left((2 k-1)^{2} \pi^{2} C_{v} / 4 H_{0}^{2}\right)}
\end{aligned}
$$

$$
\begin{gathered}
=\left(\sum _ { k = 1 } ^ { \infty } \left(2 \sqrt { s C _ { v z } } ( q + p _ { 0 } s ) \left[\cosh \left(\sqrt{\frac{s}{C_{v z}}} H_{0}\right)-\cosh \left(\sqrt{\frac{s}{C_{v z}}} H_{0}\right)\right.\right.\right. \\
\times \cosh \left(\sqrt{\left.\frac{s}{C_{v z}} z\right)+\sinh \left(\sqrt{\frac{s}{C_{v z}}} H_{0}\right)}\right. \\
\left.\times \sinh \left(\sqrt{\frac{s}{C_{v z}} z}\right)\right] \\
\left.\left.\times\left(s^{2} H_{0} \sinh \left(\sqrt{\frac{s}{C_{v z}}} H_{0}\right)\right)^{-1}\right) e^{s t}\right)\left.\right|_{s=-\left((2 k-1)^{2} \pi^{2} C_{v} / 4 H_{0}^{2}\right)} \\
=\sum_{k=1}^{\infty} \frac{\left(-4 H_{0}^{2} q+(2 k-1)^{2} \pi^{2} C_{v z} p_{0}\right) \sinh \left(\left((2 k-1) / 2 H_{0}\right) \pi z\right)}{(2 k-1)^{3} \pi^{3} C_{v z}} \\
\times e^{-\left((2 k-1)^{2} \pi^{2} C_{v z} / 4 H_{0}^{2}\right) t} .
\end{gathered}
$$

Then,

$$
\begin{aligned}
& u_{1}(z, t) \\
& \begin{array}{l}
\sum_{k=1}^{\infty} 4 \frac{\left(-4 H_{0}^{2} q+(2 k-1)^{2} \pi^{2} C_{v z} p_{0}\right) \sinh \left(\left((2 k-1) / 2 H_{0}\right) \pi z\right)}{(2 k-1)^{3} \pi^{3} C_{v z}} \\
\quad \times e^{-\left((2 k-1)^{2} \pi^{2} C_{v z} / 4 H_{0}^{2}\right) t} .
\end{array}
\end{aligned}
$$

Then, we can put (33) and (42) into (14) of total question to get the final solution. Consider

$$
\begin{aligned}
& u(z, r, t) \\
& =\frac{u_{1}(z, t) u_{2}(r, t)}{p_{0}} \\
& =\sum_{k=1}^{\infty} 2 \frac{\left[-4 H_{0}^{2} q+(2 k-1)^{2} \pi^{2} C_{v z} p_{0}\right] \sinh \left(\left((2 k-1) / 2 H_{0}\right) \pi z\right)}{p_{0}(2 k-1)^{3} \pi^{3} C_{v z}} \\
& +\sum_{k=1}^{\infty} \sum_{i=1}^{\infty}\left(4 Q\left[Y_{1}\left(B_{i} r_{e}\right) J_{0}\left(B_{i} r\right)-J_{1}\left(B_{i} r_{e}\right) Y_{0}\left(B_{i} r\right)\right]\right. \\
& \times\left(\beta_{i}^{2} \frac{r_{e}\left[J_{0}\left(r_{e} B_{i}\right)-J_{2}\left(r_{e} B_{i}\right)\right] Y_{0}\left(r_{w} B_{i}\right)}{4 C_{v r} B_{i}}\right. \\
& \left.\left.-\beta_{i}^{2} J_{0}\left(r_{w} B_{i}\right) Y_{1}\left(r_{w} B_{i}\right)\right)^{-1}\right) \\
& \quad \frac{\left(-4 H_{0}^{2} q+(2 k-1)^{2} \pi^{2} C_{v z} p_{0}\right) \sinh \left(\left((2 k-1) / 2 H_{0}\right) \pi z\right)}{p_{0}(2 k-1)^{3} \pi^{3} C_{v z}} \\
& \times e^{-\left((2 k-1)^{2} \pi^{2} C_{v z} / 4 H_{0}^{2}\right) t-\beta_{i} t} .
\end{aligned}
$$

This is the final expression of the excess hydrostatic pressure changing along the value of pole diameter of the cylindrical polar coordinates $(r)$, consolidation time $(t)$, and calculation depth $(z)$. 
TABLE 1: Scope of each calculation parameter.

\begin{tabular}{lccc}
\hline Parameter and its extremum & $\begin{array}{c}\text { Diameter of } \\
\text { sand drain } d(\mathrm{~m})\end{array}$ & $\begin{array}{c}\text { Separation distance } \\
\text { of sand drain } l(\mathrm{~m})\end{array}$ & $\begin{array}{c}\text { Loading rate } \\
(\mathrm{kPa} / \mathrm{y})\end{array}$ \\
\hline $\operatorname{Max}$ & 0.35 & 5.0 & 45 \\
$\operatorname{Min}$ & 0.10 & 1.0 & 25 \\
\hline
\end{tabular}

TABLE 2: The initial value of each calculation parameter.

\begin{tabular}{lcccc}
\hline $\begin{array}{l}\text { Diameter of } \\
\text { sand drain } d_{0}\end{array}$ & $\begin{array}{c}\text { Separation } \\
\text { distance of sand } \\
\text { drain } l_{0}\end{array}$ & $\begin{array}{c}\text { Calculation } \\
\text { depth } z_{0}\end{array}$ & $\begin{array}{c}\text { Loading rate } \\
q_{0}\end{array}$ & $\begin{array}{c}\text { Coefficient of } \\
\text { consolidation } \\
C_{v 0}\end{array}$ \\
\hline $0.30 \mathrm{~m}$ & $3.0 \mathrm{~m}$ & $20.0 \mathrm{~m}$ & $39 \mathrm{kPa} / \mathrm{y}$ & 0.002 \\
\hline
\end{tabular}

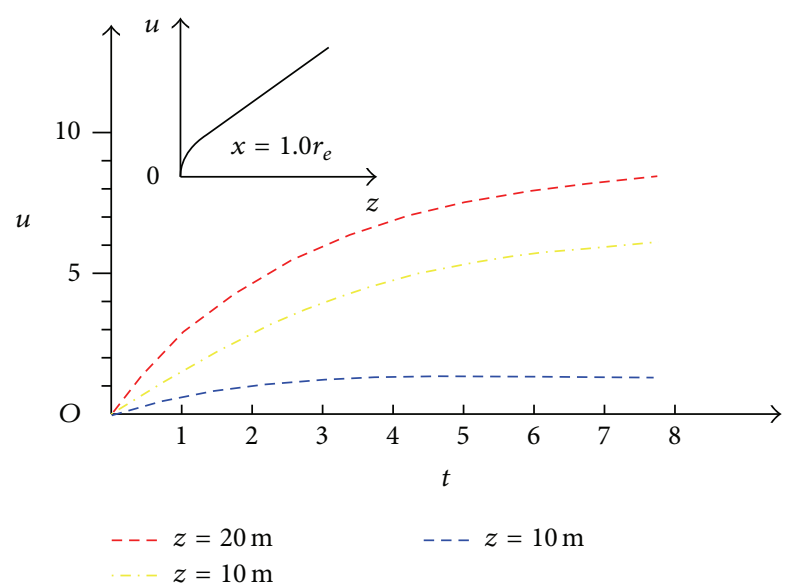

Figure 4: Pore pressure $u$ 's change curve with depth $z$.

\section{Analysis on the Change Law of the Pore Water Pressure}

From the derivation of former part of the research, the function of the excess hydrostatic pressure is influenced by multiple variables, whose variation characteristic cannot be vividly expressed in a three-dimensional space coordinate system. For the purpose of understanding the variation rule of $u$ with the time and space, we use MATLAB as a tool, by examining a parameter and fixing other parameters, to get the affects way of each variable effects on the value of $u$. Based on the previous engineering experience and based on the survey and design of tailings and actual production, scope of calculation parameter is as shown in Table 1 .

Control variate method is employed to conclude the influence of various parameters on the law of drainage. Concretely, what this means is to study the effect of target variable from the four variables, diameter $d$, separation distance $l$, loading rate $q$, and coefficient of consolidation $C_{v}$, and fix the other three ones as initial value.

On the basis of scope of each calculation parameter (Table 1), the initial values are set as Table 2.

A serious of relation curves between the excess pore water pressure and time can be obtained by successively changing

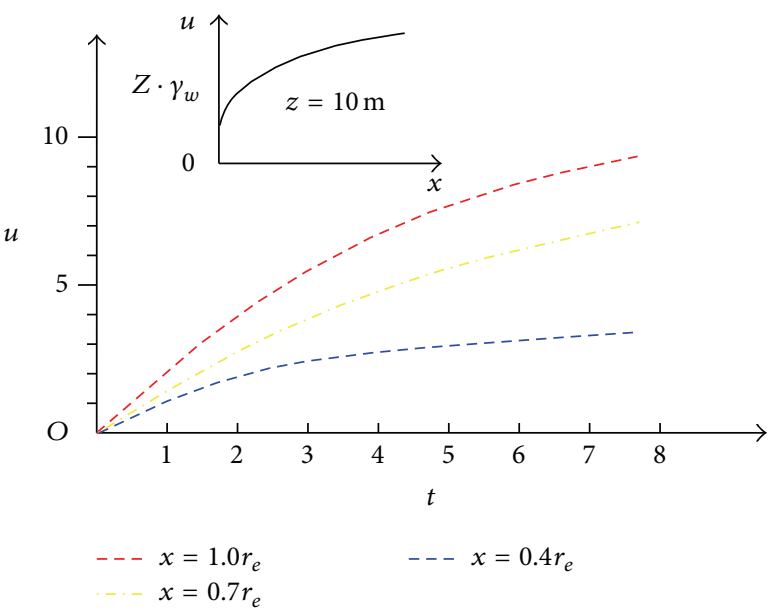

FIgURE 5: Pore pressure $u$ 's change curve with position $x$.

the above calculation parameters in proportion. Due to the fact that objective continuous loading time is less than 8 years, the maximum value of excess pore water pressure will emerge when the time value ranges in $0 \sim 8$. The variation diagrams of excess pore water pressure can be calculated and plotted via the MATLAB drawing routine PLOT and calculating routine FindRoots. All the figures are about the calculated point on the action radius and also the border of the single sand drain modeling, except Figure 5. The abscissa axis unit is year. All the curves results and discussions are as following.

(1) Under the initial parameters, the excess pore water pressure at different sites $(x, z)$ of the sand drain modeling is compared and shown as in Figures 4 and 5. And the pressure $u$ 's change curves with depth $z$ and position $x$ are also given as insets.

From Figures 4 and 5, it can be known that the excess pore water pressure in the depth vertical direction is nonlinear, and in the shade is of low change and gradient. While, in the horizontal direction, the static pore water pressure will increase slowly and have a lower final value when the distance between two sand drains is wide. Inversely, it will increase faster and 


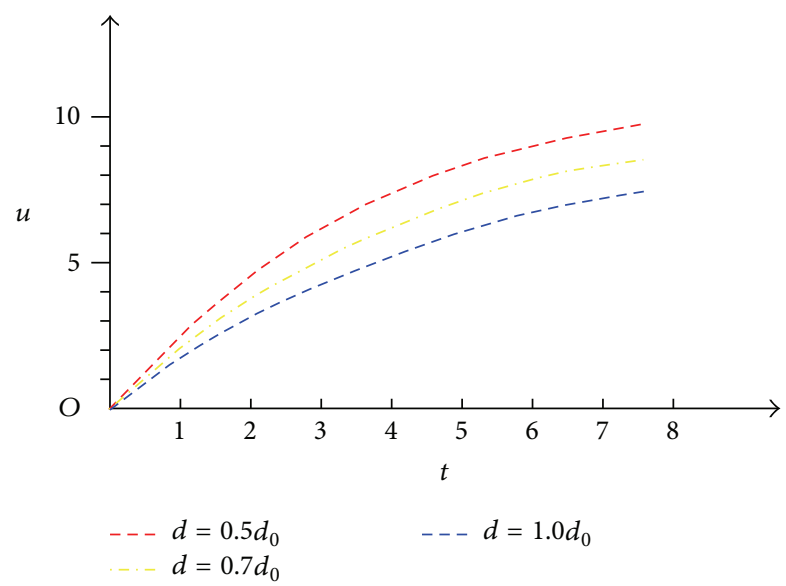

FIGURE 6: Pore pressure $u$ 's change curve with sand well's diameter d.

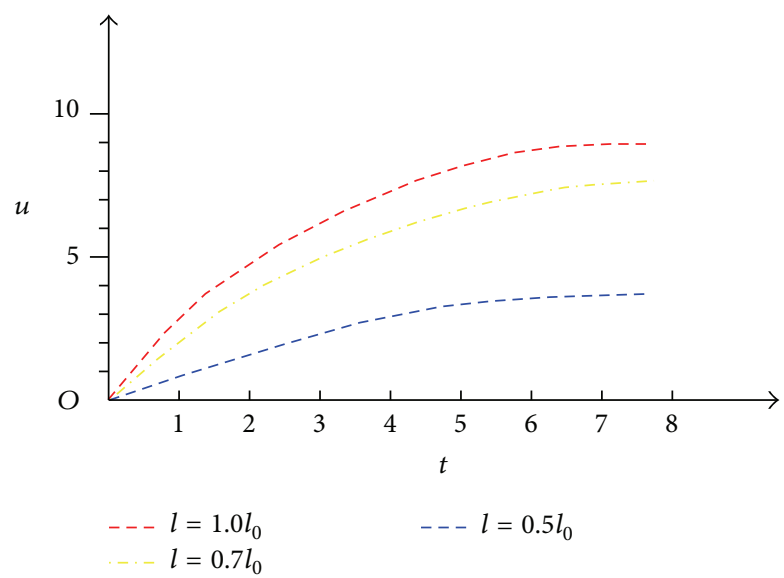

FIGURE 7: Pore pressure $u$ 's change curve with sand well's spacing $l$.

have a larger final value when the distance is narrow. What is more is that the trade is nonlinear.

(2) Under the initial parameters, change the value of separation distance of sand drain $d$ to see the influence of $d$ on static pore water pressure.

From Figure 6, it can be indicated that the conditions of all the other parameters are the same and diameter variation of sand drain can make no difference on the reduction of excess pore water pressure, which demonstrate the rationality of former assumption on a certain extent. This has come from the low permeability and loading rate of red mud.

(3) Under the initial parameters, change the value of separation distance of sand drain to see the influence of $l$ on excess pore water pressure.

From Figure 7, it can be obtained that the conditions of all the other parameters are the same and the change of the separation distance can significantly affect the change speed and the final value of excess pore water pressure. The influence of reducing the distance is more obvious than enlarging the diameter

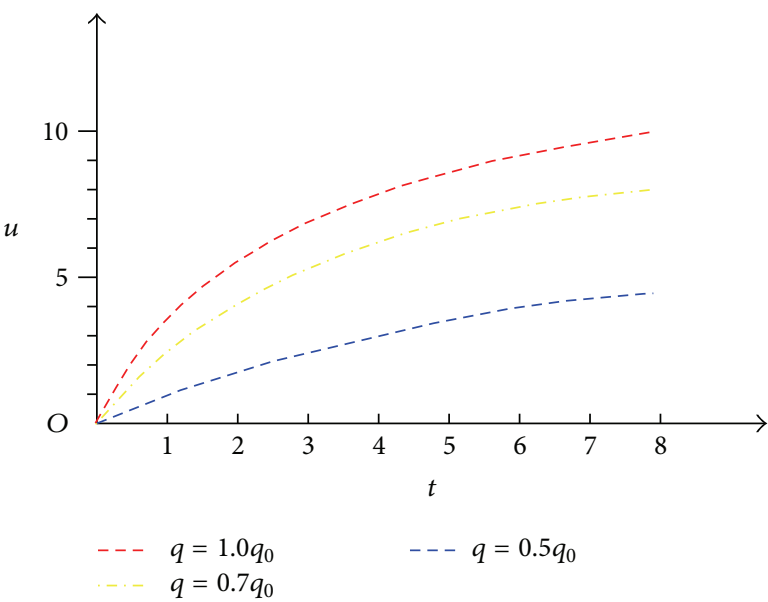

FIgURE 8: Pore pressure $u$ 's change curve with loading rate $q$.

on the pore water pressure. The final excess pore water pressure can only be one quarter of the initial value when $l$ is just half of the initial one.

(4) Under the initial parameters, change the value of loading rate to see the influence of $q$ on excess pore water pressure.

From Figure 8, it can be deduced that the conditions of all the other parameters are the same, and larger loading rate can result in larger pore water pressure. However, even if the loading rate is identical, different reduction can lead to different value of final value of excess pore water pressure. A modest reduction has a small effect and continuous reduction has an obvious effect.

(5) Under the initial parameters, change the value of coefficient of consolidation to see the influence of $C_{v}$ on static pore water pressure.

From Figure 9, it can be deduced that the conditions of all the other parameters are the same; the larger the coefficient of consolidation, the smaller the final value of excess pore water pressure, or vice versa. Consequently, applying sand wells drainage consolidation method on different pore medium, only more drainage channel or shorter drainage distance can support the consolidation effect when the consolidation time is the same, while $C_{v}$ is smaller.

\section{Conclusion}

This research has established the calculation model of single well drainage pore water pressure, deduced pore water pressure differential equation based on the three-dimensional consolidation, and get the analytical solution of differential equation using Bessel function and Laplace transform. The impact of parameters in the function on the pore water pressure is analyzed by control variable method. Changes of excess pore water pressure on four variables such as diameter $d$, separation distance $l$, loading rate $q$, and coefficient of 


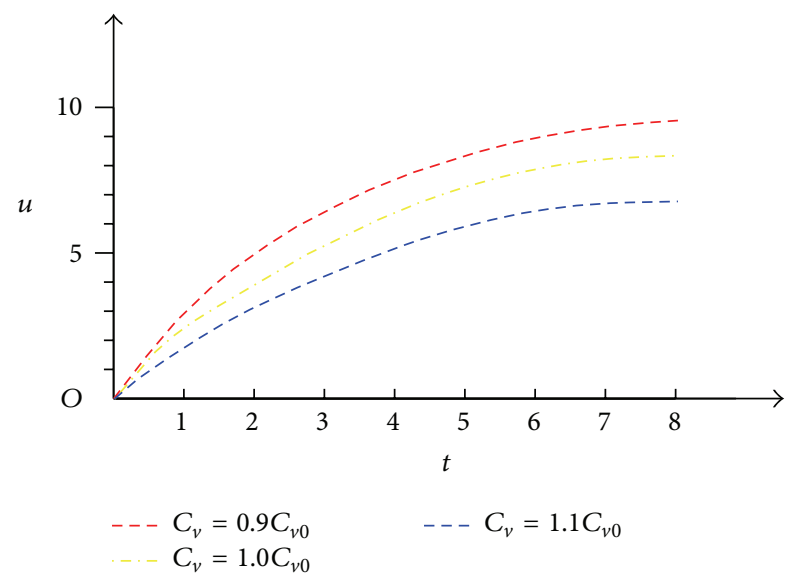

Figure 9: Pore pressure $u$ 's change curve with coefficient of consolidation $C_{v}$.

consolidation $C_{v}$ are analyzed and proved to be nonlinear. The calculation results help to further set up a depository stability evaluation model to prevent loading exceeding design capacity. And together with inhomogeneous deformation data of the field, it is promising to create warning systems for site managers based merely on the field logging data of pore pressure data. Therefore, this research has a guiding significance on preventing red mud tailings leakage of continuous loading pile exceeding design capacity.

\section{Conflict of Interests}

The author declares that there is no conflict of interests regarding the publication of this paper.

\section{References}

[1] M. Gräfe and C. Klauber, "Bauxite residue issues: IV. Old obstacles and new pathways for in situ residue bioremediation," Hydrometallurgy, vol. 108, no. 1-2, pp. 46-59, 2011.

[2] U.S. Geological Survey, "Bauxite and alumina statistics and information," in Historical Statistics for Mineral and Material Commodities in the United States, D. T. Kelly and G. R. Matos, Eds., U.S. Geological Survey, 2008.

[3] M. Gräfe, G. Power, and C. Klauber, "Bauxite residue issues: III. Alkalinity and associated chemistry," Hydrometallurgy, vol. 108, no. 1-2, pp. 60-79, 2011.

[4] J. Wehr, I. Fulton, and N. Menzies, "Revegetation strategies for bauxite refinery residue: a case study of Alcan Gove in Northern Territory, Australia," Environmental Management, vol. 37, no. 3, pp. 297-306, 2006.

[5] C. Klauber, M. Gräfe, and G. Power, "Bauxite residue issues: II. options for residue utilization," Hydrometallurgy, vol. 108, no. 1-2, pp. 11-32, 2011.

[6] R. Bott, T. Langeloh, and J. Hahn, "Re-usage of dry bauxite residue," in Proceedings of the 7th International Alumina Quality Workshop, A. McKinnon, Ed., pp. 236-241, AQW Inc., Perth, Australia, 2005.

[7] C. Brunori, C. Cremisini, P. Massanisso, V. Pinto, and L. Torricelli, "Reuse of a treated red mud bauxite waste: Studies on environmental compatibility," Journal of Hazardous Materials, vol. 117, no. 1, pp. 55-63, 2005.

[8] W. Liu, J. Yang, and B. Xiao, "Review on treatment and utilization of bauxite residues in China," International Journal of Mineral Processing, vol. 93, no. 3-4, pp. 220-231, 2009.

[9] P. Renforth, W. M. Mayes, A. P. Jarvis, I. T. Burke, D. A. C. Manning, and K. Gruiz, "Contaminant mobility and carbon sequestration downstream of the Ajka (Hungary) red mud spill: the effects of gypsum dosing," Science of the Total Environment, vol. 421-422, pp. 253-259, 2012.

[10] P. Wang and D. Y. Liu, "Physical and chemical properties of sintering red mud and bayer red mud and the implications for beneficial utilization," Materials, vol. 5, no. 10, pp. 1800-1810, 2012.

[11] C. Wu and D. Liu, "Mineral phase and physical properties of red mud calcined at different temperatures," Journal of Nanomaterials, vol. 2012, Article ID 628592, 6 pages, 2012.

[12] A. Gelencsér, N. Kováts, B. Turóczi et al., “The red mud accident in Ajka (Hungary): characterization and potential health effects of fugitive dust," Environmental Science and Technology, vol. 45, no. 4, pp. 1608-1615, 2011.

[13] W. M. Mayes, A. P. Jarvis, I. T. Burke et al., "Dispersal and attenuation of trace contaminants downstream of the ajka bauxite residue (red mud) depository failure, Hungary," Environmental Science and Technology, vol. 45, no. 12, pp. 5147-5155, 2011.

[14] J. Paul Rinehimer, J. Thomson, and C. Chris Chickadel, "Thermal observations of drainage from a mud flat," Continental Shelf Research, vol. 60, pp. S1250-S135, 2013.

[15] Q. Bi, J. Jia, and Z. Huang, "Numerical analysis for consolidation drainage scheme of red mud disposal," Journal of North China Institute of Water Conservancy and Hydroelectric Power, vol. 33, pp. 87-90, 2012.

[16] K. Terzaghi, Theoretical Soil Mechanics, John Wiley \& Sons, New York, NY, USA, 1943.

[17] A. Onoue, "Consolidation by vertical drains taking well resistance and smear into consideration," Soils and Foundations, vol. 28, no. 4, pp. 165-174, 1988.

[18] P. Orleach, Technique to evaluate the field performance of vertical drains [M.S. thesis], Massachusetts Institute of Technology, Cambridge, Mass, USA, 1983.

[19] X. W. Tang and K. Onitsuka, "Consolidation of ground with partially penetrated vertical drains," Geotechnical Engineering, vol. 29, no. 2, pp. 209-231, 1998.

[20] R. A. Barron, "Consolidation of fine-grained soils by drain wells," Transactions of the American Society of Civil Engineers, vol. 113, no. 2346, pp. 718-754, 1948.

[21] H. Yoshikuni and H. Nakanado, "Consolidation of fine-grained soils by drain well with filter permeabiiity," Soil and Foundation, vol. 14, pp. 35-46, 1974.

[22] G. X. Zeng and K. H. Xie, "New development of the vertical drain theories," in Proceedings of the 12th International Conference on Soil Mechanics and Foundation Engineering, vol. 2, pp. 1435-1438, Rio de Janeiro, Brazil, August 1989.

[23] G. Zhu and J. Yin, "Consolidation analysis of soil with vertical and horizontal drainage under ramp loading considering smear effects," Geotextiles and Geomembranes, vol. 22, no. 1-2, pp. 6374, 2004.

[24] W. Li, "Numerical simulation of sand drains foundation with a consideration of permeability coefficient changing along the radial direction," Subgrade Engineering, vol. 6, pp. 70-73, 2012. 
[25] L. Ding, D. Ling, L. Wang, and Y. Chen, "Application of composite element method in sand drain ground finite element analysis," Chinese Journal of Computational Mechanics, vol. 21, no. 1, pp. 13-20, 2004.

[26] K. Zhao and Y. Zheng, "Shear-resistance strength of red mud after consolidation and drainage," Guizhou Geology, vol. 13, pp. 280-286, 1996. 


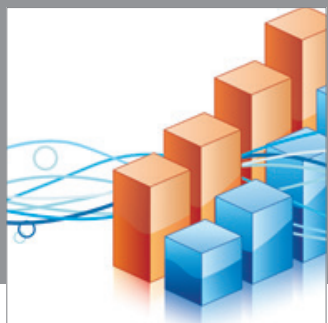

Advances in

Operations Research

mansans

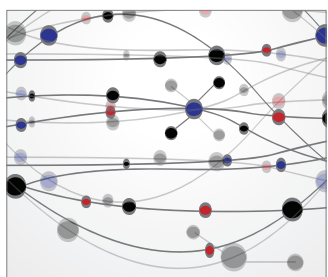

The Scientific World Journal
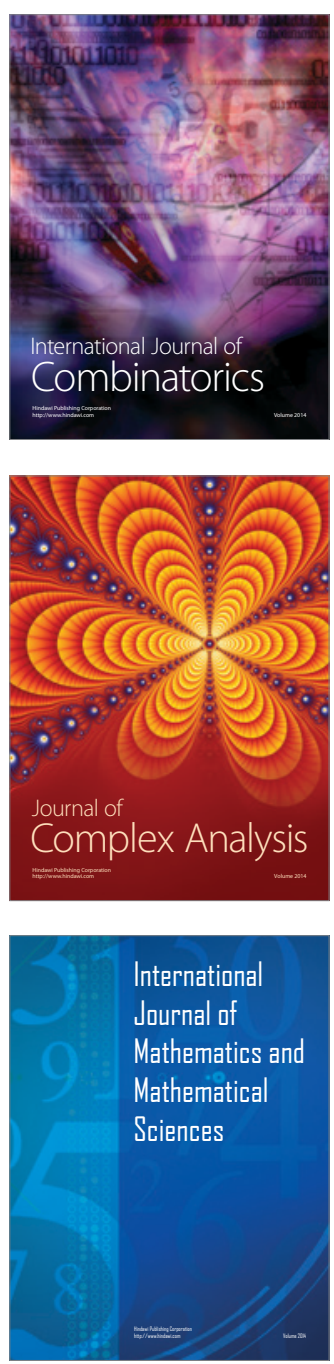
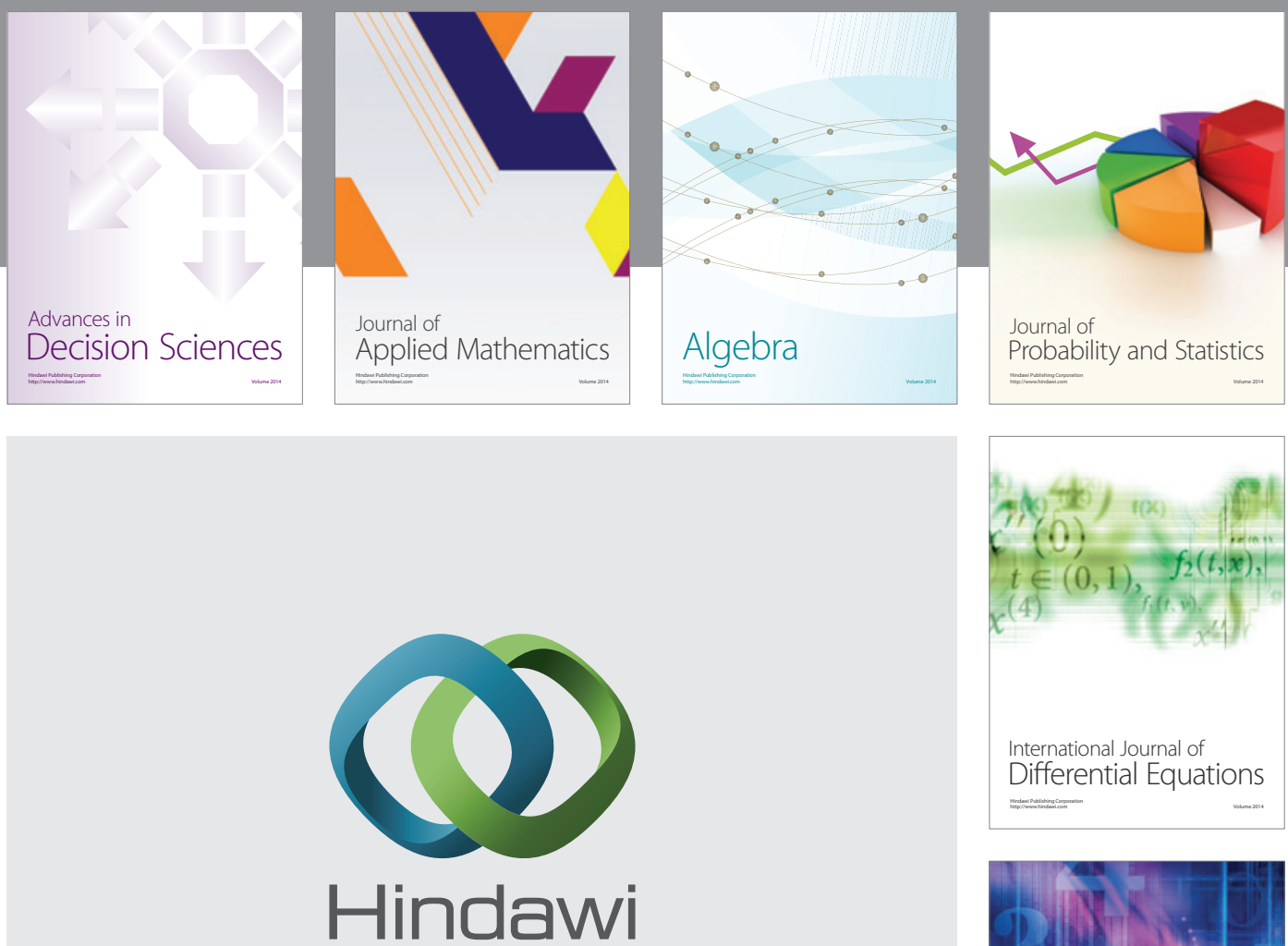

Submit your manuscripts at http://www.hindawi.com
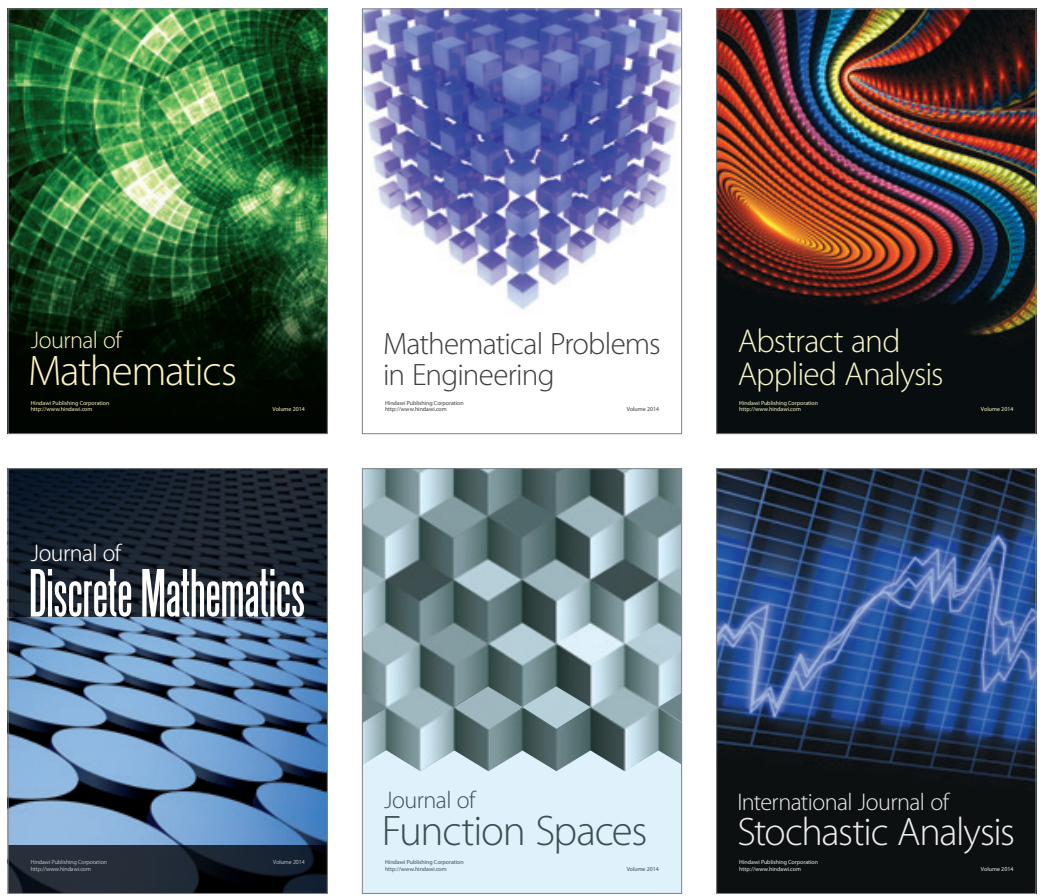

Journal of

Function Spaces

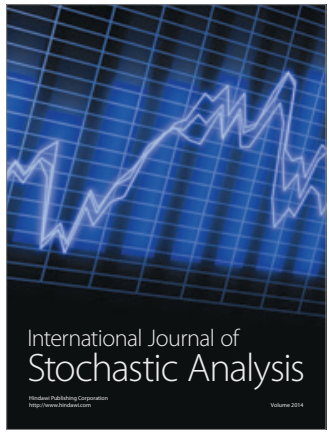

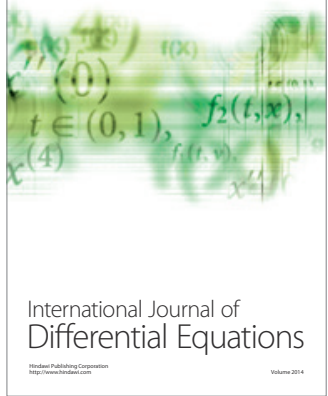
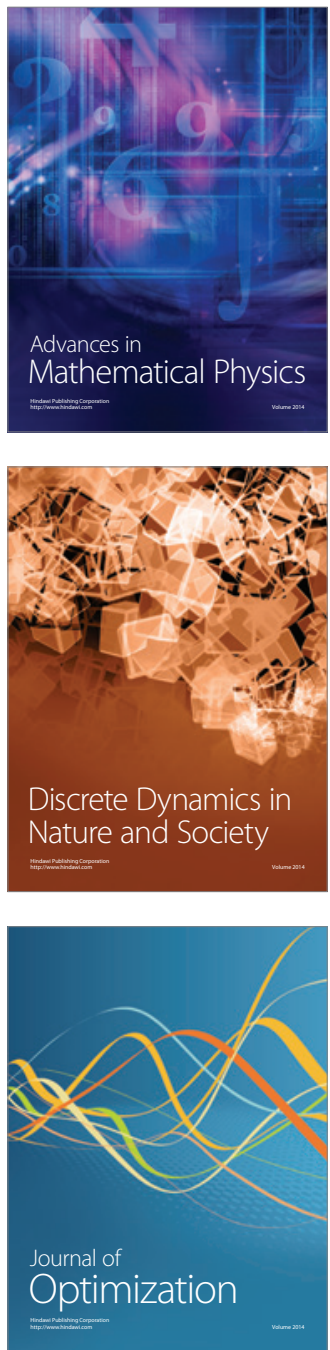